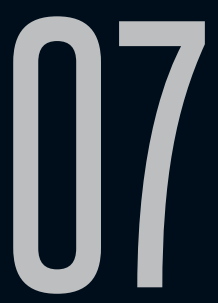

\title{
O DESEJO DE TRANSCENDER A MORTE: UM ESTUDO DE “AR FRIO”, DE H. P. LOVECRAFT
}

Daniela Pinto Vasconcelos (UFRGS) Sandra Sirangelo Maggio (UFRGS)

Recebido em 04 mar 2017. Daniela Pinto Vasconcelos tem licenciatura dupla em Aprovado em 12 abr 2017. Letras Português/Inglês pela Universidade Federal do Rio Grande do Sul (UFRGS). É professora de Português e Inglês do Curso Methodus, em Cachoeirinha. Realiza pesquisa na área de literatura inglesa, com foco na literatura gótica. Autores estudados: Lovecraft, Poe e Wilde. Lattes: http://lattes.cnpq.br/6291782468374412. E-mail: dani_celos@hotmail.com.

Sandra Sirangelo Maggio é professora classe E dos programas de graduação e pós-graduação em Letras da Universidade Federal do Rio Grande do Sul. Realiza atividades de ensino, pesquisa e extensão e orienta trabalhos de graduação, mestrado e doutorado em Literaturas de Língua Inglesa, tendo como foco principal de atuação e pesquisa a literatura dos períodos vitoriano e eduardiano. Lattes: http://lattes. cnpq.br/0866814477504163. Página pessoal: https// sandramaggio.wordpress.com. E-mail: ssmaggio@ yahoo.com.br.

Resumo: O presente trabalho analisa a vontade de transcender a morte, a partir de uma leitura do conto "Ar frio", de H. P. Lovecraft. Nessa história, o Dr. Munõz utiliza seus conhecimentos científicos para 
postergar a própria morte, pagando um preço caro por esse empreendimento. Nosso objetivo é discutir os motivos que fazem com que a personagem se esforce para reverter um processo irreversível, o do ciclo natural da vida. Entre os fatores considerados estão o medo do desconhecido, o receio de deixar de existir, a vontade altruísta de aperfeiçoar a própria espécie, o anseio pela expansão do domínio e do poder, a pretensão de passar do papel de criatura ao papel de criador. Na busca da longevidade, as circunstâncias do Dr. Munõz se tornam cada vez mais limitadas, acabando por transformar o viver em uma morte em vida e chegando, por fim, ao fracasso do plano da personagem, que vai então ao encontro da morte definitiva. Partindo do pressuposto de que o desejo de transcendência é intrínseco ao ser humano, buscamos identificar como esse anseio transgressor é visto na nossa cultura, na literatura e na ficção de Lovecraft.

Palavras-chave: Medo da morte; Busca pela longevidade; A morte na literatura; H. P. Lovecraft; "Ar frio".

Abstract: The present work consists of an analysis of the urge to transcend death, focusing on a reading of the short story "Cold Air", by H. P. Lovecraft. In the story, Dr. Muñoz uses the scientific knowledge he has to postpone his own death, paying a high price for the endeavor. Our goal is to discuss the reasons why the character tries to reverse a process that is irreversible: the natural cycle of life. Among the factors considered, we have the fear of the unknown, the dread of ceasing to exist, the selfless wish to improve the condition of our own species, the longing for power, and the will to turn form the role of creature into the role of Creator. In this search for longevity, the circumstances of Dr. Muñoz become more and more limited, until his life turns into a living death. Eventually, there comes the failure of his plan and the character finally dies. Based 
on the assumption that the desire for transcendence is inherent to man, we seek to identify the ways in which such desire is seen in our culture, in literature, and in Lovecraft's fiction.

Keywords: Fear of death; Quest for longevity; Death in literature; H. P. Lovecraft; "Cold Air".

A fome só se satisfaz com a comida e a fome de imortalidade da alma com a própria imortalidade.

Ambas são verdadeiros instintos.

(Fernando Pessoa, Poemas)

\section{INTRODUÇÃO}

Um problema que vem atormentando a raça humana desde sempre - e assim produzindo grandes frutos na área da literatura - é até que ponto o homem pode e deve (ou não) transcender os limites que se Ihe apresentam. Desde os tempos primordiais, os fenômenos da natureza foram sendo explicados como manifestações divinas, do deus do sol, do deus da chuva, do deus do vento. A esses deuses foi atribuído o poder sobre todas as coisas, o poder de controle da natureza e o poder de conduzir a essência de um ser para outras esferas depois de cumprido o ciclo da vida do corpo. Seja nos cultos politeístas, seja nos monoteístas, essa ingerência sobre a vida e sobre a morte é território dos deuses. Ainda assim, temos os grandes transgressores, como Prometeu, Pandora, Adão e Eva - e o Dr. Munõz, de Lovecraft. A partir de um certo ponto no desenvolvimento da nossa cultura, ocorreu a clivagem entre os domínios da ciência e os da religião, que podem ou não andar juntas, dependendo da filosofia ou teologia adotada. Em todas as crenças, como em todos os sistemas sociais, temos a presença 
da proibição, do interdito, uma ordem ou um conselho para que o ser humano não se aventure além dos territórios que domina com segurança. Esse interdito é justificado, e mesmo necessário, porque se cada um resolvesse agir de sua maneira o convívio social ficaria comprometido. Mas ocorre que sempre existe a exceção que justifica a regra, e toda e qualquer ordem sempre será descumprida. Isso nos lembra o princípio básico da neurolinguística, que informa que o cérebro humano não está programado para registrar a partícula "não" em uma frase. A linha teológica conhecida como Felix Culpa propõe que o que é esperado do ser humano é justamente que ele transgrida, como se nossa espécie fosse programada para se desenvolver através da desobediência, do pecado, ou da transcendência (AQUINO, 1997). Dessa forma, Eva está cumprindo o plano de Deus quando convida Adão para provar da árvore do fruto do conhecimento. Esse parece ser o dilema da raça humana: questionar tudo o tempo todo é perigoso e pode levar à destruição do corpo social e à extinção da espécie. Por outro lado, refrear o desejo de transcender seria desmerecer a curiosidade, que é a característica que move o desenvolvimento humano. Assim, articulando leis, códigos de ética, códigos morais, chegamos aos tempos de hoje, aos estudos genéticos com células tronco e às câmaras de criogenia.

Com a evolução do intelecto e com todas as descobertas realizadas, a ciência está aos poucos decifrando os mecanismos de criar vida e fazer nascer. Experiências são feitas em laboratórios em torno de descobertas genéticas. O desejo de criar caminha junto com o desejo de "fazer durar", ou seja, de estender a vida o quanto seja possível. Não se trata necessariamente (ainda) de vencer a 
morte, mas de prolongar a vida. Esse processo de "tomar para si - papel dos deuses" gera medo e ansiedade. Não sabemos se a melhor alternativa é confiar no ciclo da natureza e sermos otimistas, na esperança de que haja mesmo algum tipo de continuação da vida no próximo estágio; ou se devemos, se pudermos, procurar outras alternativas.

Os grandes transgressores da literatura, de Prometeu a Victor Frankenstein, são ao mesmo tempo admirados e reprovados tanto pelos leitores quanto pelo ponto de vista narrativo das obras em que se inserem. Quando o estudante Victor Frankenstein decide fazer um experimento de (re)criação de vida, esse seu ato representa muitas coisas. Como cientista, ele desenvolve um projeto sem medir consequências para chegar ao objetivo proposto. Utiliza os instrumentos que a educação tradicional lhe oferece, e também os de áreas secretas e restritas, como manuais de alquimia proibidos para o uso de leigos. Enquanto realiza a experiência, ele mesmo se define como alguém que está fazendo algo errado, alçando-se por conta própria ao papel de Deus. No conto de Lovecraft, o Dr. Munõz não parece estar procurando a fama e o reconhecimento que Frankenstein almeja, nem mesmo quer promover algum grande benefício para a humanidade. Ele está simplesmente fugindo da morte. Seu instinto de sobrevivência entra em ação e ele faz o que acha que pode fazer para escapar dessa realidade desconhecida.

Quando lemos textos como "Ar frio", realizamos atos psicológicos que se alinham a essa fuga do desconhecido. Assim como o narrador sem nome de "Ar frio", ficamos fascinados pelo ato transgressor do protagonista, que evoca situações sobre as quais nos sentimos divididos. Por um lado, gostaríamos de ter o 
conhecimento e a coragem para transpor barreiras em territórios novos e perigosos ligados à ciência, à ética, à moralidade, à religião. Por outro lado, temos um receio sensato dos resultados, que a literatura, a ética e a religião costumam apontar como perigosos. De qualquer forma, a literatura e a arte representam válvulas de escape para essa tensão que existe em nós.

Outra maneira de lidarmos com esse medo é aceitando o fato e deixando o ciclo da vida seguir seu curso. A saída mais utilizada nos dias de hoje é buscar o alívio para a ansiedade através do consumo. Consumir nos traz a sensação de controle. Quando compramos um creme que rejuvenesce sentimos que ganhamos algum tempo de volta; se adquirimos um bem de consumo achamos que - pelo menos por hoje - estamos vivos, vencemos a batalha diária contra a morte. Sentimo-nos como o animal primitivo que conseguiu trazer a caça para dentro da caverna, garantindo mais um tempo de sobrevida. Assim é cada dia a mais vivido pelo Dr. Munõz, que não se contenta com o pouco tempo que teria ao natural, acreditando que a vida é curta demais e precisa ser estendida, seja como for.

\section{APRESENTANDO O CONTO DE LOVECRAFT}

No conteúdo parafraseável do conto "Ar frio", nos deparamos com um narrador perturbado que conta sua história como uma forma de justificar o seu estranho temor pelo frio e sua repulsa pelo cheiro de amônia. O narrador relata um episódio que ocorreu quando se instalou em um quarto de pensão em uma casa antiga. Nessa pensão, após sofrer um infarto súbito, conhece um médico doente, também morador de lá, que estranhamente vive preso em seu quarto, refugiado no frio produzido por uma máquina 
que, segundo ele, é necessária para o tratamento de sua moléstia. O quarto é descrito como destoante da realidade decadente do local: tem móveis novos e de qualidade, é bem decorado e limpo, apresentando não somente um luxo estranho ao lugar, mas representando a educação e classe superiores do morador. Após o choque pelo contato inicial e a cura de sua doença pelo médico, o narrador começa a se interessar e admirar o conhecimento e os estudos do velho adoentado. Aos poucos, ele começa a se tornar uma espécie de discípulo ajudante, fazendo os serviços da casa e atendendo aos caprichos do Dr. Munõz, enquanto, paulatinamente, o médico vai definhando.

A trama se desenrola a partir do ponto em que a máquina que mantém o ambiente frio quebra no meio da noite, causando a elevação da temperatura e arriscando a integridade física do Dr. Munõz. O narrador tenta de todas as formas encontrar uma solução para o problema, contratando um rapaz para levar sacos de gelo até o quarto enquanto ele busca por alguém que possa consertar a máquina. O tempo passa, o dia corre e, ao voltar para a pensão, o narrador sente que um cheiro forte de putrefação tomou a mansão, descobrindo, logo em seguida, que o cheiro vem dos aposentos do Dr. Muñoz. Ao entrar, encontra uma carta do médico atestando que ele próprio havia sido o experimento de comprovação de sua teoria - de que o corpo pode sobreviver após a falência dos órgãos apenas pela força da mente - e revelando que ele, na verdade, havia morrido dezoito anos antes. Próximo à carta está o corpo completamente apodrecido do médico.

A história é apresentada ao estilo de Lovecraft, que em muito lembra o de Edgar Allan Poe. "Ar frio" claramente homenageia 
o conto de Poe "Os fatos do caso do Sr. Valdemar", escrito oito décadas antes. A relação entre esses dois autores tão semelhantes é analisada por Yuri Garcia no artigo "Lovecraft e Poe: ressonâncias nos contos dos mestres do horror e suas criações de sensações e ambiências", onde temos o trecho:

Lovecraft, de fato, havia sido um grande admirador de Poe, e em diversas de suas cartas e textos, revela ter se inspirado imensamente em sua obra. Contudo, ao analisarmos as obras de Poe, destacamos uma que dialoga também com diversas criações encontradas na mitologia de Lovecraft e que pode ter sido uma importante influência na criação do Cthulhu Mythos. (GARCIA, 2015, p.6)

James Cooper Lawrence, ao tratar sobre o gênero conto (short story) a partir do estudo de Poe, salienta ainda a importância de a história satisfazer os seguintes requisitos: “(1) deve ser breve e (2) deve ser suficientemente coesa para reter de forma absoluta o interesse do leitor ou da audiência do início ao fim" (LAWRENCE, 1917, p. 275) ${ }^{1}$.

Além disso, Lawrence afirma que pode ainda haver algumas categorias para a definição de conto segundo as quais a narrativa de Lovecraft se encaixaria em um conto contado de forma histórica, ou seja, algo que é apresentado exatamente do modo como aconteceu, em tom realista. Essas reflexões se encaixam em "Ar frio", pois o narrador tem o intuito de contar o fato que ocorreu em sua vida que justificaria os seus medos e, dessa forma, desloca o leitor para o seu ponto de vista, fazendo com que ele descubra, junto com o narrador/personagem, os mistérios do 1 No original, em inglês: "(1) that it shall be short and (2) that it shall possess coherence sufficient to hold the reader's or listener's unflagging interest from beginning to the end". 
estranho vizinho de quarto. Este artifício, que Lovecraft desenrola com maestria, faz com que a história se torne envolvente para o leitor e contribua para o ar de mistério da trama. Por outro lado, essa condição de conto faz com que grande parte das informações e/ou explicações acerca das reais intenções e desejos do Dr. Muñoz não fiquem esclarecidas ou fiquem apenas subentendidas, cabendo ao leitor fazer a sua interpretação do que está por trás de todo o acontecimento, considerando que um conto precisa ser breve e objetivo, evitando maiores explicações além do necessário e, é claro, também pelo fato de o narrador ser uma personagem da história, o que nos limita a saber apenas o que o narrador sabe por experiência própria.

\section{A BUSCA DE CONTROLE E PODER}

O mistério que circunda as temáticas da morte ao longo do conto já é expresso no momento em que o narrador começa a se relacionar com o Dr. Muñoz:

Ao mesmo tempo, assegurou-me, com uma voz modulada, ainda que oca e sem timbre, que era o mais ferrenho inimigo da morte e que havia gasto toda a sua fortuna e perdido todos os amigos ao longo de uma vida de experimentos devotados à sua derrota e aniquilação. (LOVECRAFT, 2014, p.58)

É possível ver, aqui, que o desejo de vencer a morte perpassa toda a vida do médico, que admite ter perdido tudo o que tinha na busca de atingir seu objetivo. Esse desejo pode ser entendido de duas maneiras. A primeira é como uma vontade intrínseca de poder, que faz com que ele queira se sobressair fazendo algo que ninguém ainda conseguiu. A segunda é a expressão de um medo 
enrustido e mascarado, que faz com que o médico tente a qualquer custo prolongar a vida apesar da condição de morte do corpo.

No primeiro ponto, essa vontade de adquirir poder lembra a necessidade de ascensão na carreira médica. Ele é um médico excepcional, mas isso não basta para se sentir realizado, pois falta ainda comprovar sua teoria sobre o domínio do corpo pela mente. O Dr. Muñoz não busca vencer as barreiras da morte apenas para testar suas possibilidades ou para poder desfrutar melhor sua vida, mas como uma forma de provar para si e para o mundo o poder da ciência e de seus estudos. Isso se comprova pelo fato de que ele faz pesquisas e cria a sua teoria, porém não tem um plano sobre como compartilhar essa vitória com outras pessoas. O cunho pessoal da jornada do Dr. Munõz é comprovado quando percebemos que ele só criou o seu projeto depois de receber o diagnóstico que indicava que ele estava morrendo. A partir disso, decidiu testar suas teorias em si mesmo, por ser essa, talvez, a sua única chance de sobrevivência. Isso pode ser visto no trecho:

O Dr. Torres sabia, mas o choque matou-o. Ele não suportou o que tinha de fazer - precisou levar-me a um lugar estranho e escuro quando deu atenção à minha carta e me trouxe de volta. Mas os órgãos jamais voltaram a funcionar. Tinha de ser feito à minha moda - preservação - pois fique sabendo que morri dezoito anos atrás. (LOVECRAFT, 2014, p.63)

Vê-se que não havia no início uma intenção de provar a teoria em si mesma, ela veio de uma necessidade, visto que os procedimentos normais não haviam funcionado. Não há aqui, de forma alguma, a ideia de que a morte faz parte da natureza humana 
e não pode ser controlada, pelo contrário: para ele, a natureza é como um obstáculo a ser vencido pela ciência, provando que o homem tem, de fato, controle sobre ela e sobre tudo ao seu redor.

O segundo ponto, o que retrata o medo humano de morrer, pode ser considerado com base no fato de que o médico não tenta apenas fazer um experimento consigo mesmo, anotando avanços e aceitando quando o experimento prático não condiz com os resultados esperados, entregando-se à morte. O Dr. Muñoz aceita experimentar em si a sua teoria com base em um desejo de permanecer vivo. Quando ele afirma que a sua cura tinha de ser feita à sua moda de preservação, confessa um medo de que nada funcione e que tenha de enfrentar a dura realidade da morte, em consequência de seu fracasso.

Da mesma forma, vemos o decorrer da história com as observações do narrador com base na forma de agir do doutor, sua moléstia e a maneira como encara isso. Apesar de perceber que o experimento não está funcionando como desejado, o médico não desiste de sua teoria, ou seja, não desiste de sua vida. No trecho a seguir, vemos a sua insistente determinação em não se entregar:

Com o passar das semanas, notei, com grande pesar, que meu novo amigo estava de fato perdendo o vigor físico aos poucos, mas de forma incontestável, como a sra. Herrero havia mencionado. $\mathrm{O}$ aspecto lívido em seu semblante intensificara-se, a voz tornara-se mais vazia e indistinta, os movimentos musculares coordenavam-se de maneira cada vez menos perfeita e a mente e a determinação apresentavam-se menos constantes e menos ativas. O Dr. Muñoz não parecia alheio a essas tristes mudanças, e aos poucos seu rosto e sua voz 
assumiram um tom de terrível ironia, que me fez sentir mais uma vez a leve repulsa que eu sentira no início. [...] Uma espécie de horror crescente, de origem singular e mórbida, dava a impressão de possuí-lo. O inválido discorria sem parar sobre a morte, mas dava gargalhadas ocas quando se falava em enterro ou em procedimentos funerários. (LOVECRAFT, 2014, p.59-60)

Aqui, vemos que a vitalidade do médico já está se esvaindo, mas há ainda uma negação quanto à ideia de morte: um "horror crescente, de origem singular e mórbida, dava a impressão de possuí-lo" (LOVECRAFT, 2014, p.59), fazendo com que ele se esforce mais para permanecer vivo e para esconder os segredos da sua prática. Quanto mais ele percebe a chegada definitiva da morte, tanto mais isso o aterroriza.

Para o filósofo alemão Friedrich Nietzsche, essa busca pelo controle é uma característica do ser humano: "Este mundo é a vontade de poder - e nada além disso! E também vós mesmos sois essa vontade de poder - e nada além disso!" (NIETZSCHE, 2008, p.513). A ideia de poder está relacionada às noções de autoridade $e$ domínio, ou seja, o indivíduo tem a escolha sobre o destino de algo, sobre as mudanças a serem (ou não) feitas. Esse domínio perpassa os desejos humanos desde os tempos mais antigos, na formação dos grupos e sociedades, na escravização de povos, na hierarquização de funções sociais, nas mais diversas formas de governo ou mesmo na formação familiar. O homem dominou a natureza, o conhecimento, os povos, o dinheiro, o pensamento coletivo, enfim, o domínio e o poder formam as engrenagens das mais diversas áreas da sociedade. Porém, há domínios que o homem ainda não pode alcançar, nem 
compreender. Esses domínios foram por muito tempo atribuídos a uma outra esfera, a da divindade. Resta, contudo, o tabu de tomar o papel de Deus e dominar a última fronteira, que é a divisa com a morte. Por sua condição delicada, o Dr. Munõz se vê pressionado a atravessar os limites do interdito. Nas palavras de Ernst Tugendhat, em "Nietzsche e o problema da transcendência imanente", "a vontade de poder podia ser entendida como uma fonte de ação que por si mesma pressiona a um além e que isso é o que dá sentido à vida" (TUGENDHAT, 2002, p.3).

Além do olhar de Nietzsche, que problematiza a questão a partir da vontade de poder, há ainda outras formas de encarar esse fenômeno inexplicável e inevitável em seu sentido prático, visto que não temos como saber com precisão o que acontece com um ser após o fim de sua existência. Essa falta de compreensão sobre o que acontecerá, ou não, depois que a barreira da morte for transposta vem sendo objeto de estudos filosóficos desde sempre. Faremos a seguir um breve apanhado de algumas ideias que consideramos parte da discussão suscitada por esta leitura de "Ar Frio".

\section{A MORTE, POR DIFERENTES OLHARES}

Há quem diga, como Voltaire, que a raça humana é a única que compreende que vai morrer, e sabe isso através da experiência (VOLTAIRE, 2002). Obviamente, Voltaire sabe que todos os animais sabem sobre a morte. Quanto mais primitiva a condição de vida de um animal, mais ele exerce, a cada minuto, suas habilidades para escapar da morte. A diferença entre o ser humano e as demais espécies animais é que, por ter a capacidade de raciocínio mais desenvolvida, tendo o cérebro equipado com a estrutura da 
linguagem, os humanos realizam elucubrações mais complexas com respeito ao ciclo da vida, à inevitabilidade da morte e à incerteza sobre o que vem depois.

Segundo Bellato e Carvalho em O jogo existencial e a ritualização da morte,

Embora compartilhem o nascimento, a doença, a juventude, a maturidade, a velhice e a morte com os animais, apenas os seres humanos, dentre todos os seres vivos, sabem que morrerão. Assim, a imagem da morte tem acompanhado o existir humano desde seu alvorecer, abrindo enorme vazio diante da vida, representado por um aterrorizante não-ser inominável. (BELLATO e CARVALHO, 2005, p.100)

Apesar de a morte ser uma certeza do ser humano, essa certeza perpassa o desconhecido, pois o que acontece após o óbito ainda é um mistério para a mente humana. Há quem creia na eternidade da alma, há quem imagine que o ser desaparece por completo após a morte, mas a verdade é que não sabemos com precisão e provas o que realmente acontece após a morte. Essa incerteza causa o medo que, consequentemente, provoca o desejo de fuga, o instinto de querer ser imortal apenas para não ter de enfrentar o desconhecido. Ainda no texto de Bellato e Carvalho, vemos a seguinte reflexão:

É preciso lembrar que o 'horror da morte', esse fantasma que sempre acompanhou o ser humano, e que se traduz pela dor do funeral, pelo terror da decomposição do cadáver e pela obsessão da morte, tem por denominador comum a 'perda da individualidade'. Essa dor pela perda será tanto maior quanto mais próximo ou significativo for o morto para a família ou a comunidade. Portanto, 
não é o fenômeno da putrefação em si que traz o terror, mas a emoção, o sentimento ou a consciência da perda da individualidade, quando o morto não está individualizado, isto é, não reconhecido como ser humano. (BELLATO e CARVALHO, 2005, p.101)

Isso significa que o ser humano tem medo de perder a sua essência, perder a sua individualidade, não sabendo o que acontecerá consigo (se sua alma permanecerá viva em algum outro plano ou se sua existência findará por completo), tendo apenas a certeza de que após a morte o corpo deixa de ser "reconhecido como humano". Esses medos e desejos levam a pessoa a refletir sobre a sua existência e sobre o domínio que exerce na natureza. Foi dominando os mistérios biológicos que a ciência pôde descobrir o funcionamento do corpo humano, dos animais e dos meios naturais, podendo utilizar esse conhecimento e domínio para o próprio benefício humano. Através do domínio das leis da física e da química, a formação da matéria e as mais diversas reações entre elementos, foi possível criar remédios, máquinas e os mais variados tipos de objetos. Foi através da dominação humana sobre o planeta e sobre si mesmo que se chegou ao nível de vida que presenciamos hoje, utilizando de tudo para facilitar e melhorar o trabalho e as relações das pessoas com o mundo.

Outro ponto de discordância entre os filósofos é a questão de como lidar com o fato de que vamos morrer. Para Heidegger, a consciência sobre a morte é uma estrutura imanente, que existe a priori na consciência humana. Para ele, existem diferentes níveis de consciência, e mesmo quando pensamos que não estamos pensando na morte, estamos enganados, devido a mecanismos internos de repressão (HEIDEGGER, 2010). Freud, por sua vez, diz o 
contrário. Para ele, o que é superficial é a consciência da morte, pois o nosso inconsciente tem convicção de que somos imortais. Para Freud, não é possível nem sequer alguém imaginar a própria morte, porque quando faz isso, sobrevive na condição de espectador da cena (FREUD, 1989). Enfim, independentemente do que se diga ou ache a respeito, a perspectiva da morte envolve medo. Pode ser o medo de parar de existir, o medo de perder alguém querido, o medo de passar por uma experiência dolorosa e torturante, de perder a consciência, a capacidade de pensar. Descartes dizia: "Penso, logo, existo" (DESCARTES, 2001). Por isso mesmo, o fim da possibilidade de pensar é uma ideia intolerável.

As interpretações da morte têm representações diferentes em épocas diferentes. Em muitos mitos, e em textos literários, como no poema "Annabel Lee", de Edgar Alan Poe, por exemplo, a morte é atribuída à inveja de deuses e demônios para com a felicidade humana. Nas religiões, a vivência da fé oferece a esperança de uma passagem tranquila para outros estágios de vida depois da morte. Já na Idade Média, a morte é apresentada como um castigo para o pecado inerente à natureza humana. Com ou sem a convicção de que exista algo depois, o que não se questiona é que o ser humano é avesso ao desconhecido. Por melhores que sejam os prospectos em uma possível existência posterior à morte, é desagradável a ideia de perder aquilo que se trabalhou a vida inteira para construir. O medo que circunda esses mistérios é perfeitamente comum e compreensível.

O entendimento da morte varia também conforme as influências sociais que o indivíduo recebe em sua vivência, considerando não apenas sua crença, religião ou ceticismo, 
mas também o grau de segurança oferecido pela comunidade em que está inserido. De acordo com o historiador Johan Huizinga, a preocupação com a morte está diretamente ligada ao individualismo, intensificando-se nos períodos em que há maior instabilidade e inconformidade aos valores sociais. Huizinga dá como exemplos, na sociedade clássica, a época que segue a desintegração das cidades-estado e o início do Renascimento, ao término do feudalismo (HUIZINGA, 1989).

Tecnicamente, o medo nada mais é do que um mecanismo de defesa que alerta o corpo sobre um possível perigo. A reação mais natural de alguém com medo é tentar fugir, escapar, desviarse daquilo que representa um risco para a integridade do corpo. Tendo isso considerado, o ser humano passa a sua vida fugindo da morte, a cada segundo de cada dia. Procura viver de modo a protelar o quanto seja possível o encontro indesejado com a morte. O pensador francês Jean Baudrillard escreve sobre como os veículos midiáticos promovem uma constante fuga contra a morte, das mais diferentes maneiras, apresentando diversos tipos de produções que transmitem a falsa ideia de que a vida pode ser editada como uma imagem ou como um filme (BAUDRILLARD, 1991). Em toda a parte encontramos matérias jornalísticas sobre a longevidade da população de alguns países orientais, e sobre como eles alcançaram isso; programas televisivos que sugerem alimentos saudáveis que podem ajudar a viver por mais tempo; pesquisas científicas que desenvolvem remédios e/ou estudos sobre elementos da natureza que retardam o envelhecimento. Essa busca incessante pelo aumento do tempo de vida do corpo e demora no processo de envelhecimento retrata uma sociedade que receia a morte e 
procura sempre evitá-la ou adiá-la. Quais seriam os limites éticos dessa fuga da morte? Nos textos literários que lidam com essa temática, a tendência - que se confirma no caso de "Ar Frio" - é que a transgressão fracasse no final.

\section{CONCLUSÃO}

Qual é, afinal, o objetivo do Dr. Muñoz? Não parece ser a busca do poder, ou a fama, ou prestar um serviço à humanidade. O que ele procura é fugir da morte porque ela representa para ele o fim da existência. A filosofia do Dr. Munõz é a de que é melhor viver mal do que não viver. É possível que, na parte final de sua vida, ele se movimente apenas pelo hábito dos rituais diários da sobrevivência. Se parasse para pensar, talvez concluísse que existem coisas ainda piores do que deixar de existir, como a não-vida que ele está levando. Talvez, também, se estivesse mais satisfeito com as coisas que conseguiu fazer enquanto tinha saúde, conseguisse se desapegar melhor no momento de parar de viver.

O Dr. Munõz está certo ou errado em sua tentativa de vencer a morte? Como vimos anteriormente, diferentes linhas de pensamento têm respostas diferentes para esta pergunta. Mas fechando o foco na questão que nos compete, a da literatura, podemos afirmar que a maneira como "Ar Frio" é construído, as palavras ali escritas e a estrutura com que o texto é composto e narrado, preparam o leitor para o fracasso da experiência do Dr. Munõz. Voltando às raízes gregas de nossa tradição literária, lembramos o que diz Aristóteles, para quem uma das funções principais da arte é contribuir para a ordem social. Por isso, não é adequado que na ficção os bons sejam prejudicados, ou que os maus sejam recompensados: 
Em primeiro lugar, é óbvio não ser conveniente mostrar pessoas de bem passar da felicidade ao infortúnio (pois tal figura produz, não temor e compaixão, mas uma impressão desagradável); nem convém representar homens maus passando do crime à prosperidade (de todos os resultados, este é o mais oposto ao trágico, pois, faltandoIhe todos os requisitos para tal efeito, não inspira nenhum dos sentimentos naturais ao homem nem compaixão, nem temor); nem um homem completamente perverso deve tombar da felicidade no infortúnio (tal situação pode suscitar em nós um sentimento de humanidade, mas sem provocar compaixão nem temor). (ARISTÓTELES, 1998, p.19)

Não sabemos se o Dr. Muñoz é um homem bom ou mau, isso não vem ao caso para a história. Mas sabemos que ele está cometendo um ato de transgressão, algo que - para a ética de Aristóteles - pode ser prejudicial para a polis. Assim, a ética de "Ar frio" se alinha ao projeto aristotélico. E nós, mesmo sendo leitores versáteis do século XXI, também somos levados a esperar que a experiência fracasse no final. Sabemos que existem muitos tipos de textos na literatura e na arte contemporânea em que o horizonte de expectativas do leitor é quebrado (JAUSS, 1994), mas quando se trata da clássica luta contra a morte isso não costuma acontecer. A tendência é que as experiências científicas ou os atos de magia fracassem no final, como se o ser humano tivesse de ser recolocado no seu lugar (por um criador meio irritado, meio divertido), por mais uma transgressão cometida.

Talvez um motivo por que as tentativas de vencer a morte fracassem na literatura é que esse é predominantemente um tema 
Gótico, com ênfase no registro da putrefação, da dor prolongada, da decrepitude e escuridão derivadas do pecado da transgressão. Freud, em seu texto sobre o estranho "Das Unheimliche", no qual investiga os motivos por que histórias de terror ao mesmo tempo nos apavoram e nos fascinam, comenta que - dependendo do gênero da ficção - há ocasiões em que "voltar da morte" é tomado com naturalidade, como quando Branca de Neve abre os olhos e retoma sua vida (FREUD, 2006).

Em "Ar Frio", o ponto alto do horror na história é representado pelo cheiro de putrefação, um cheiro que, nos tempos primitivos, devia ser muito conhecido do olfato humano. Mas, na medida em que a vida em sociedade se tornou mais sofisticada e asséptica, as marcas da presença da morte passaram a ser evitadas. Como comentado anteriormente, de acordo com Huizinga (1989) quanto mais em crise está uma sociedade, mais fortemente se impõe o tema do medo da morte. Considerando o estado da literatura atual, parece que estamos em um momento de pico nessa marcação. Claudio Zanini analisa como essas questões se colocam na obra do escritor contemporâneo Chuck Palahniuk, exímio em retratar sintomas de "comportamentos característicos da sociedade pósmoderna", porta-voz "da dificuldade dos indivíduos de lidar com as exigências e constantes mudanças nos âmbitos pessoal, social e psicológico" (ZANINI, 2008, p.6).

O mundo em que vive o Dr. Munõz já prenuncia os dias de hoje. Durante certo tempo, ele vislumbra a imortalidade, e se esforça por capturar essa miragem, dando tudo de si para alcançar seu objetivo. Mas o tipo de sobrevida que consegue mais parece os miasmas de um cadáver em putrefação. Ao invés de uma afirmação do sucesso 
do homem sobre a morte, essa história funciona mesmo como um lembrete de que há coisas piores do que morrer. Como no campo da teoria aristotélica uma ousadia desmedida tem grandes riscos de terminar mal, é isso o que ocorre em "Ar Frio", quando a tentativa de domínio desemboca no fracasso, com o método da natureza continuando a prevalecer no final.

O desejo de dominar o envelhecimento e a morte permanece, ainda assim, como um tema sedutor. Talvez esse seja o destino dos seres humanos: viver buscando a transcendência, quebrando barreiras, adentrando campos de domínio ainda não imaginados. Foi assim que a nossa espécie evoluiu em inteligência e em conhecimento. Esse é o caminho pelo qual ela permanecerá evoluindo e se expandindo. Contanto que, com sorte, ou com a ingerência dos seres superiores, ela não se autodestrua no processo.

Talvez dentro de alguns milênios não exista mais vida na Terra, nem ninguém para apreciar os textos literários que anteciparam os desastres ocorridos. Ou então viveremos em uma civilização bem organizada, na qual os limites da vida tenham sido consideravelmente ampliados. Não é totalmente impossível que um dia seja atingida uma qualidade de convívio entre as pessoas que torne as preocupações de Aristóteles desnecessárias. Independentemente do que se pense a respeito, por enquanto permanece o fato de que, tanto na vida como na literatura, a morte continua sendo um tabu para o ser humano. Sabemos o que temos agora, e o quanto nos custou construir o que temos; e não sabemos sobre o depois, nem se existe um depois. Também temos medo do processo da morte, da possível dor envolvida. E não queremos perder aqueles de quem gostamos e/ou de quem precisamos. Mesmo como espécie, lembra 
o reverendo John Donne, "A morte de qualquer homem diminui a mim, porque na humanidade me encontro envolvido; por isso, nunca mandes perguntar por quem os sinos dobram, eles dobram por ti" (DONNE, 2016)2.

\section{REFERÊNCIAS}

AQUINO, Tomás de (1993). Suma teológica. Carlos-Josaphat de Oliveira (Trad.). Vol. VIII, artigo 26. São Paulo: Loyola.

ARISTÓTELES (1998). Poética. Eudoro de Sousa (Trad.). 5.ed. Lisboa: Casa da Moeda. BAUDRILLARD, Jean (1991). Simulacros e simulação. Maria João da Costa Pereira (Trad.). São Paulo: Relógio d'Água.

BELLATO, Roseney; CARVALHO, Emília Campos de (2005). O jogo existencial e a ritualização da morte. Revista Latino-am Enfermagem 13(1), São Paulo.

DEATH. (1967). The Encyclopaedia of philosophy. Paul Edwards (Eds.). Nova York: MacMillan.

DESCARTES, René (2001). Discurso do método. Maria E. Galvão (Trad.). São Paulo: Martins Fontes.

DONNE, John (2007). "Meditação 17". In: . Meditações. Paulo Vizióli (Trad.). In http://www.algumapoesia.com.br/poesia2/poesianet206.htm. Acesso em 30.Out.2016.

FREUD, Sigmund (2006). "O estranho", de Jayme Salomão (Trad.). In: Sigmund Freud: obras completas. Vol. XVII. Edição Standard Brasileira, Rio: Imago.

(1989). "The future of an illusion". In: GAY, Peter (Eds.). The Freud reader. Alix Strachey (Trad.). Nova York: W. W. Norton. p.685-722.

GARCIA, Yuri (2015). Lovecraft e Poe: ressonâncias nos contos dos mestres do horror e suas criações de sensações e ambiências. Congresso Internacional Comunicação e Consumo. Rio: UERJ.

HEIDEGGER, Martin (2010). Being and time. Joan Stambaugh (Trad.). 2.ed. Nova York: State University of New York.

2 Tradução de Paulo Vizióli para o original: "[A]ny man's death diminishes me, because I am involved in mankind, and therefore never send to know for whom the bell tolls; it tolls for thee" (DONNE, 2016). 
HUIZINGA, Johan (1989). Men and ideas: History, the Middle Ages, the Renaissance. James S. Holmes e Hans van Marle (Trad.). Princeton: Princeton University Press.

JAUSS, Hans Robert (1994). A história da literatura como provocação à teoria literária. Sérgio Tellaroli (Trad.). São Paulo: Ática.

LAWRENCE, James Cooper (1917). A theory of the short story. In http://www. unz.org/Pub/NorthAmericanRev-1917feb-00274. Acesso em 20.Out.2016.

LOVECRAFT, Howard Phillips (2014). "Ar frio". In: Ar frio. Guilherme da

S. Braga (Trad.). São Paulo: Hedra.

NIETZSCHE, Friedrich (2008). A vontade de poder. Marcos S. P. Fernandes e Francisco J. D. de Moraes (Trad.). Rio: Contraponto.

POE, Edgar Alan (2012). "Annabel Lee". In: The Norton anthology of American literature. Vol. B. Oitava edição. Nina Baym (Eds.) Nova York: W. W. Norton.

TUGENDHAT, Ernst (2002). Nietzsche e o problema da transcendência imanente. Ethic@ Revista Internacional de Filosofia da Moral, 1(1). Florianópolis.

VOLTAIRE, François Marie Arouet (2002). Dicionário filosófico. Líbero R. de Tarso (Trad.). São Paulo: Editora Martin Claret.

ZANINI, Claudio Vescia (2011). The orgy is over: phantasies, fake realities and the loss of boundaries in Chuck Palahniuk's Haunted. Tese de doutorado (p.299). PPG Letras UFRGS. Instituto de Letras. Porto Alegre. 